\title{
THE BUILDING PLAN APPROVAL PROCESS FOR RESIDENTIAL DEVELOPMENT IN ONE STOP CENTRE. CASE STUDY: SUBANG JAYA MUNICIPAL COUNCIL, SELANGOR
}

\author{
Marlyana Azyyati Marzukhi ${ }^{1 *}$, Oliver Ling Hoon Leh ${ }^{1}$, Nurul Shakila Khalid ${ }^{1}$, \\ Azfarnizam Jaafar ${ }^{2}$ \\ ${ }^{1}$ Centre of Studies for Town and Regional Planning, Faculty of Architecture, Planning \& Surveying, \\ Universiti Teknologi MARA, Puncak Alam, Selangor, Malaysia. \\ ${ }^{2}$ Subang Jaya Municipal Council, Selangor, Malaysia. \\ E-mail: *marlyana@uitm.edu.my
}

\begin{abstract}
The building plan approval involved with regulations, laws and guidelines to ensure systematic and orderly development. The growth in construction activities in Malaysia since the 1980's has given rise to the need for more statutory controls in obtaining permissions from the relevant authorities to initiate and to construct a facility and upon its completion to occupy and use the completed facility. The understanding of building plan process is important to understand whether the development follows the building regulations. Thus, the construction failures can be limited. Nevertheless, little is known about the effectiveness of building plan process in the local authority though the enhancement of mechanism delivery system of the process known as One Stop Centre (OSC) has been established. The study was conducted to investigate the effectiveness of building plan approval process in Subang Jaya Municipal Council (MPSJ). Forty-seven (47) questionnaires survey has been distributed to respondents from the MPSJ's internal technical departments. Most of the respondents felt that the ineffectiveness of the building plan approval process was due to the incomplete documents submitted to the OSC, lack of knowledge among the Principal Submitting Person (PSP) and the incapability of staffs in handling development applications. The findings present a synthesis of results for town planners, architects, developers and government agencies to have a better understanding of how the effective and efficient building plan process can rationalize the success of property development sector in Malaysia.
\end{abstract}

Keywords: Development, One Stop Centre, Delivery System, Building Plan, Planning Process.

\section{INTRODUCTION}

Cities are rapidly expanding around the world. Population in most developing nation will double in size and the city areas could even triple in numbers in 2030 (United Nations, 2016). By 2025, it is also expected that the market volume of the construction industry could reach $\$ 15$ trillion and it is forecast to grow by $70 \%$ or more (Global Construction 2025 Report, 2013). The Sustainable Development Goals (SDG) have given new impetus to improve city developments. And as stated in Goal 13, it is crucial to "develop effective, accountable and transparent institutions at all levels" and to "ensure responsive, inclusive, participatory and representative decision-making at all levels" (United Nations, 2017).

The rise in population and rapid urbanization has led to an increased demand for local authorities' services. Situations such as difficulty in enforcing standards, laws, or guidelines in order to deliver efficient and comprehensive services due to shortages in budgets and resources are seldom faced by developed nations. As claimed by Muller (200), many developers tend to build buildings without obtaining complete approvals from the local authority due to complicated and costly procedures. In fact, Hernando (2000) claimed that, it is estimated 60-80\% of building projects 
in developing countries were developed without proper approvals from local authorities.

To ensure the effectiveness of laws and regulatory practices of the government, the enacted laws and related institutional machineries established at the national, state and local levels should be regularly assessed, especially for public officials who design, implement, monitor and enforce laws and regulations (United Nations, 1992). Thus, this study is important to identify the effectiveness of building plan approval processes in local authortiy to ensure efficient, fast, and competitive approval processes, particularly in Subang Jaya Municipal Council, Selangor.

\section{LITERATURE REVIEW}

In Malaysia, the approval of building plan is a vital aspect in the development process. This includes, the application for development approval, building plan approval, infrastructure plan approval and other necessary processes to ensure the Principal Submitting Plan (PSP) in charge of the building complies with all the laws and regulations enacted by the government. In fact, no one should be allowed to begin any development projects without a written consent from the local authority. PSP are required to submit all the relevant drawings, reports and designs to the Local Authority, then, Local Authority will have to go through the documents and give relevant comments and recommendations based on their requirements. These procedures are crucial to ensure that the project will be delivered as per law and regulation, thus protecting the public interest and their rights.

The development process is divided into three stages, namely; the preliminary construction stage, the construction stage, and completion stage. The building plan approval, which is in the preliminary stage, is the most essential stage in development as it will determine the exact date for construction to begin. In fact, the application and approval of building plan is the first step before development can start. This step to ensure that development plans will be reviewed by qualified personnel's to limit the risk of construction failures. A development project, that involves construction, renovation, addition, removing or clearing of an existing building (demolition) is all considered as construction and development works. If one has started any construction on site while they are yet to acquire the building plan approval, they are considered to have breached the law (Section 70, Act 133, 1974). Therefore, a building plan approval is needed before any work may commence on any proposed development. As stated in the Town and Country Planning Act 1976, no one shall be permitted to start any developments without written consent from the local authorities. The written consent is granted if all relevant plans and documents complies with the standards and requirements of local authority. After a person is granted the formal approval (building plan approval) by the relevant parties (normally the local council) under the building act (or building code), he may carry out any building works on the ground.

The local authority play important roles to ensure that all applications related to construction works follow all the rules and legislations. The information and records of the related construction works shall be accessible to all authorised personnel, such as, the current or subsequent owners. And the local authority shall be responsible for maintaining the information and records. Hence, no building or development can be erected without any approval from the local planning authority. To erect a building, the local planning authority may require details related to access, 'setbacks', elevations, design, site levels or any other details that the local authority consider necessary for a building. The details have to be written on the plan and other documents that are prepared by the qualified person that is entitled by the law.

In construction, time and procedures are the biggest "regulatory impediment" in development process. According to Nguyen (2004), the timely completion of a project that is not only within the budget but also in accordance to specifications and stakeholders' satisfaction are important aspects that will benefit the project owner (developer) and the property buyer. However, time taken by authorities, especially for the issuance of design approvals are uncertain and difficult to predict (Kincaid, 2003). In fact, the decision-making process, consideration and procedures are not stated in any laws or by-laws resulting in the differing ways of decision-making policies by local authority. Similarly, a case study carried out by Mitropoulos and Howell (2002) found that the main reason for the delay in refurbishment projects was the process of getting approvals from the local authority. When delays occur, the overall cost for the project would also be affected. McKim et al. (2000) mentioned that one of the factors contributing to cost and schedule overruns is the regulatory requirements. In some cases, the drawings had to be submitted more than once due to the amendments needed to be incorporated. This is sometimes due to the complexity of requirements set by the respective authorities (McKim, 2000).

In order to overcome the delay in building plan applications process, the Ministry of Housing and Local Government has proposed a standard, uniform work-flow chart that can be implemented simultaneously at all agencies 
involved. In this sense, the ministry has agreed with the Strategic Thrust Committee on Government Delivery System chaired by the Chief Secretary to the Government, to set up a local centre at two levels; in the local authority and state authority levels to facilitate the building plan approval processes and the release of certificates of occupation (Fadzil, 2007). With the establishment of this local centre; which was then renamed to One-Stop Centre (OSC); the application process norms could be shortened, improving the delivery system at the local authority level. In this regard, an OSC Committee was established and authorised to consider and decide upon the application for planning permissions, building plans and inform planning approvals, simultaneous applications of subdivision and change of conditions, and the surrender as well as re-alienation to the land administrator (Ministry of Housing and Local Government, 2007).

The OSC Department serves two (2) functions in the building plan application; the first being the forming of a secretariat, the OSC Secretariat, who takes care of all the development submissions in the local authority. Another function of the OSC Department is to form the OSC Committee Meeting that acts as the entity that decides on any development proposals. For all development proposals, the norms of application time must be processed within four (4) months. The OSC Secretariat should consist of Town Planning Officers from the Town Planning Department at the local authorities who are not involved in processing land developments. The OSC Secretariat functions to receive proposals for development of planning permission applications, building plan applications and land work plans from applicants. The secretariat then examines whether the proposed development proposal meets the basic requirements or conditions set by the Local Authorities. Once cleared, the secretariat will then make the distribution of the proposed development to the technical agency or the concerned parties for technical review. After the distribution, the OSC Secretariat monitors the applications that have been distributed to the technical agencies and also inform the OSC Committee of the proposed development proposals. OSC Secretariat will finally gather feedback from the technical agencies on any issues and problems with regards to the proposed development.

The OSC Secretariat shall submit a certificate paper regarding the development proposals together with a preliminary plan to obtain approvals from the OSC Committee. Once cleared, the secretariat will distribute the decisions of the OSC Committee on approving the development proposals to Land Administrators, covering:-

a. Application for land development under sections 124, 124A and 204D of the National Land Code 1965

b. Application for planning permission

c. Application for building plan

Apart from all the responsibilities stated earlier, the OSC Secretariat also acts as a secretariat in OSC Committee meetings, to set dates and ensure that meetings are held twice a month; as well as to provide meeting minutes and updates for circulation to members of the OSC Committee. The secretariat then prepares a brief that summarises all the approved development proposals and brings the brief to the Full Council Meeting of Local Authority. This is done in order to obtain a confirmation on the applications for planning permission and building plan applications. Finally, the secretariat must distribute the official decisions to the applicants via mail.

Applicants who submitted the building plan to the OSC shall ensure the application contain complete information and documents in accordance with the designated check-list. Then, the OSC Secretariat will register the application and take immediate action to distribute land-related applications (change of conditions, subdivision, simultaneous change of conditions and subdivision, surrender and re-alienation) to land offices. While applications for planning permission will be sent to the Town Planning Department and building plan applications to the Building Department at the local authority. Also, the OSC Secretariat will distribute the three applications to related external technical departments for comments and views.

The external technical departments involved, namely the State Town and Country Planning Department, the Public Works Department, the Department of Irrigation and Drainage, etcetera should provide technical comments for submission to the Local Secretariat. If a technical agency does not have time to comment in writing before an OSC Committee meeting, the review should be submitted during the meeting. To facilitate the meeting, a list of technical reviews are provided for reference to the Chairman and members of the meeting. The OSC Committee Meeting will be notified from time to time by the Secretariat of the Local Centre regarding the number and status of applications received by the Secretariat.

Meanwhile, the functions of the OSC Committee are as follows:

i. to consider and decide on the applications for planning permission and building plan applications (authority discharged by the Full Council of Local Authority); 
ii. confirmation / endorsement of planning approvals to the Land Administrator to enable State Government to consider the application under section 124, 124A, 204D of National Land Code; and

iii. to inform the Land Administrator and the Director of Lands and Mines of the approved planning approvals before the State Government considers the applications under sections 135, 124A and 204D of National Land Code.

The OSC Committee line-up, the quorum, is expected to contain twenty-one (21) members. The OSC Committee shall be chaired by the Mayor or President of the City Council, or the President of the Municipal Council, or the President of the District Council. The Town Planning Officer at the respective local authorities, normally its Director, takes on the role of secretary for the committee. Both the Chairman and the Secretary are joined by four (4) Council Member from the respective local authorities. According to the Ministry of Housing and Local Government (2007), the rest of the committee shall consist of:

1. One (1) representative from the Building Department of the local authority

2. One (1) representative from the Engineering Department of the local authority

3. One (1) representative from the Landscape Department of the local authority

4. One (1) representative from the Health Department of the local authority

5. One (1) representative from the State Town and Country Planning Department (JPBD)

6. One (1) representative from Land and Mine Office / District Land Administrator (PTD)

7. One (1) representative from the Public Works Department (JKR)

8. One (1) representative from the Department of Irrigation and Drainage (JPS)

9. One (1) representative from the Environmental Department

10. One (1) representative from the Water Supply Department (SYABAS)

11. One (1) representative from the Tenaga Nasional Berhad (TNB)

12. One (1) representative from the Fire and Rescue Department Malaysia (JBPM)

13. One (1) representative from the Telekom Malaysia Berhad (Telekom)

14. One (1) representative from the Sewerage Services Department (Indah Water Konsortium or IWK)

15. One (1) representative from the Department of Minerals and Geosciences (JMG)

Related technical departments will be invited from time to time, subject to requirements. Consultants or applicants will be invited to the presentation if necessary.

\section{CASE STUDY AND METHOD}

The study focuses on the effectiveness of building plan approval processes in Subang Jaya Municipal Council. The identification of effectiveness are referred to the capability of producing a desired result or the ability to produce desired output. When something is deemed effective, it means that it has an intended or expected outcome, or have produced a deep, vivid impression. Effectiveness in its simplest form is being able to achieve a desired result, which can be expressed quantitatively, and generally does not require much complicated mathematical equations other than additions. Accordingly, governments are bound to ensure effectiveness of laws and regulation practices among agencies, consultants and other relevant organisations to the (United Nation, 1992). In this sense, the enacted laws and other related institutional machineries across national, state and local government should be regularly assessed, especially on those who are in charge in designs, implementations, monitoring and law enforcers.

\subsection{Case study}

The Subang Jaya Municipal Council (MPSJ) was established in accordance with the Local Government Act 1976 (Act 171) under Section 4. The authority area covers 161.8 square kilometres. It consists of two (2) sub-districts namely Damansara and Petaling. MPSJ is located in a strategic area as it borders the Kuala Lumpur City Hall (DBKL), Shah Alam City Council (MBSA), Petaling Jaya City Council (MBPJ) and the Klang Municipal Council (MPK) (Fig. 1.). 


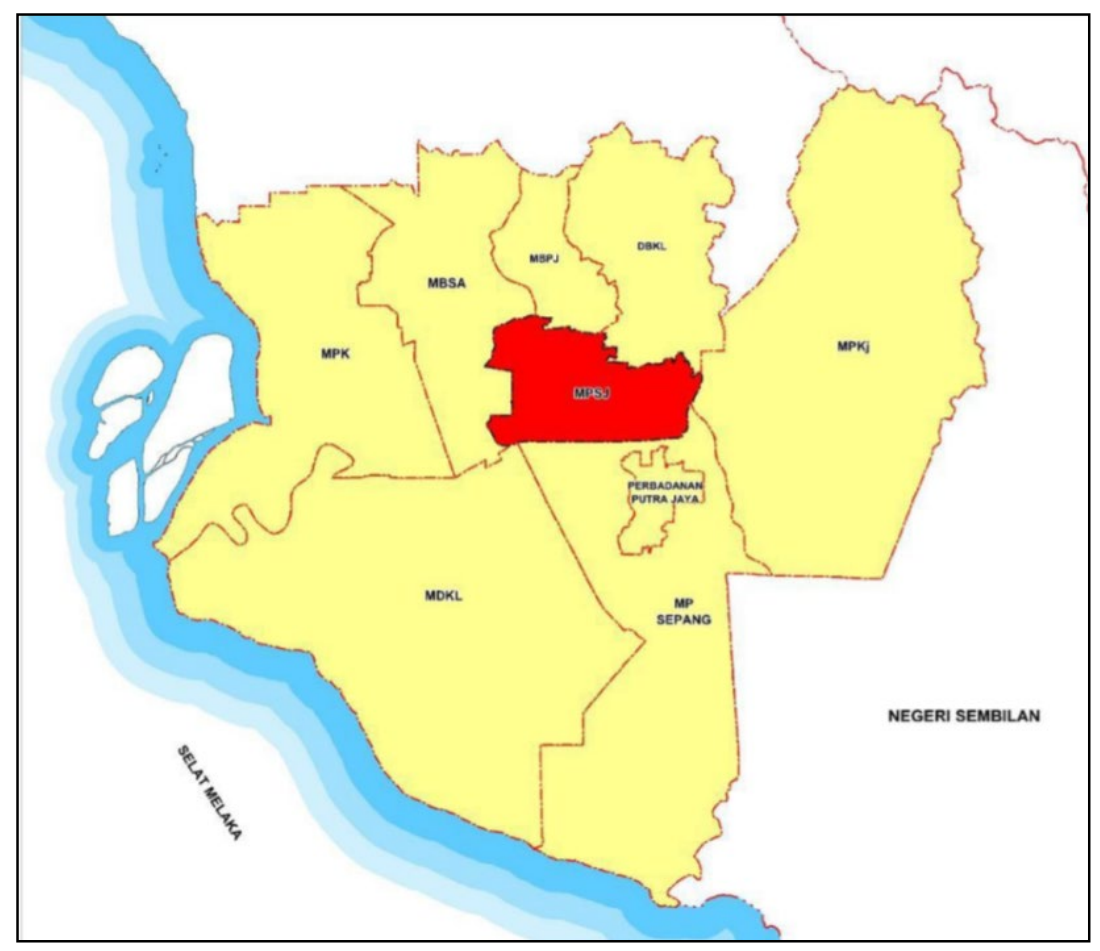

Fig. 1. Local Authority Boundary in Selangor Source: Subang Jaya Local Plan (2020)

\subsection{Questionnaire survey}

The questionnaire is design to collect information regarding the roles of the OSC Department, the building plan procedures, and related issues in Subang Jaya Municipal Council (MPSJ). A total of forty-seven (47) respondents were selected from the MPSJ's internal technical departments by using purposive sampling method. A set of questionnaire was distributed to the internal technical departments of MPSJ to find out more about the capabilities of the OSC Department in handling development applications submitted at MPSJ. Only the MPSJ internal technical departments were required to answer the questionnaire as they have better knowledge and are alerted constantly in regards to the development application procedures at MPSJ in comparison to external technical departments such as the Fire Department of Malaysia (JBPM) and Indah Water Konsortium (IWK). Besides that, any amendments to the OSC application procedures require the internal technical department to also alter the work procedures of respective departments. Since JBPM and IWK are not under the administration and management of MPSJ, amendments to OSC procedures for development applications on their part are usually not made.

Respondents were asked to answer questions in the questionnaire based on five-point scales to indicate their agreement or disagreement by ticking (/) appropriately on the scales provided. The five-point scale varies from Strongly Disagree, Disagree, Neutral, Agree and Strongly Agree. The five-point scale statements can be found from Question 1 to Question 7 (in Section B), Question 1 to Question 6 (in Section C) and Question 1 to Question 6 (in Section D). The respondents were also advised to state their opinion by filling in the blank areas. This is reflected in Question 8 and 9 (Section B), Question 7 and 8 (Section C) and Question 7 (Section D). There are twenty-four (24) questions in the questionnaire. The questions in Section B require officers from the technical department to reflect on issues related to the application for approval of development plans at MPSJ. This includes the OSC Committee meetings, legislative aspects and difficulties during the application. Section B has a total of eight (8) questions.

For questions in Section C, the officers are require to give feedback on the roles of the OSC Department and the efficiency of this department in handling the application for new developments submitted to MPSJ. Section C has a total of eight (8) questions. While Section D require the respondents to answer questions in regards to the time stated in the OSC Procedure for the processing of new building permit applications. Section D is important to identify whether the officers within the internal technical departments are familiar with the time frames and durations of OSC work. Forty-seven (47) sets of questionnaires were distributed to four (4) MPSJ's internal technical departments. The related departments include the OSC Department, the Building Department, the Town Planning Department and the 
Engineering Department. From the forty-seven (47) sets of questionnaires, seven (7) sets were distributed to the OSC Department, eight (8) sets were distributed to the Engineering Department, ten (10) sets were distributed to the Building Department and twenty-two (22) sets distributed to the Town Planning Department.

\subsection{Method of analysis}

The analysis was conducted to find out the effectiveness of building plan approval processes in Subang Jaya Municipal Council. Statistical Package for Social Science (SPSS) software was used to analyse the data.

\section{RESULTS AND DISCUSSION}

The analysis was focussed on the satisfaction level of respondents in regards to the issues of building plan approvals in OSC and the role of the OSC in MPSJ. Finally, the OSC procedures and time frames in the local authority were discussed.

\subsection{Issues in building plan approval}

The questions required officers from all selected technical departments to answer issues in regards to the application of building plans process at MPSJ. Some of the issues related to the handling of applications at the MPSJ such as the OSC Committee meetings, legal requirements and difficulties during the application.

Fourteen (14) respondents agreed that the officers in MPSJ were constantly being reshuffled (29.79\%), but (9) respondents (19.15\%) disagreed. Most of the respondents $(51.06 \%, 24$ respondents) were unsure whether the reshuffling was constantly done but agreed that most of the PSP lacked knowledge in the job. However, twenty one (21) respondents claimed that building plan procedures in MPSJ were very complex and diffciult to comply (44.68\%), and the procedures involved too many departments and officers $(65.96 \%, 31$ respondents).

According to 35 respondents (74.47\%), the letters sent to MPSJ are managed according to a hierarchical order and the officers in charge will normally receive the letters on different day, which further create delay. Due to lack of knowledge, some of the PSP have often present MPSJ with incomplete documents during discussions and preconsultations (59.57\%, 28 respondents), thus causing further delays in the process. Nevertheless, MPSJ claimed that the requirements for building plans $(51.06 \%, 24$ respondents $)$ and the statutory clocks $(51.06 \%, 24$ respondents $)$ have been fully understood by all related parties. Thirty-three (33) respondents $(70.21 \%)$ stated that they would like to have an online notification system to be adopted by MPSJ which they claimed can combat the delay caused by postal mails.

Table 1. Issues in building plan approval

\begin{tabular}{|c|c|c|c|c|c|}
\hline Issues in building plan approval & 1 & 2 & 3 & 4 & 5 \\
\hline 1 Inadequate officers & 5 & 10 & 17 & 11 & 4 \\
\hline 2 Officers of local authority not familiar with OSC procedures & 3 & 22 & 13 & 8 & 1 \\
\hline 3 Constant reshuffling of officers in local authority & 3 & 6 & 24 & 12 & 2 \\
\hline 4 Building plan applicants lack of knowledge & - & 6 & 17 & 20 & 4 \\
\hline 5 Strict regulations for building plan procedures/applications & 1 & 8 & 17 & 16 & 5 \\
\hline 6 Involves too many officers in the department & - & 6 & 10 & 27 & 4 \\
\hline $\begin{array}{l}7 \text { Lack of transparency in pre-consultations, fee calculations, plan requirements } \\
\text { etc. }\end{array}$ & 5 & 15 & 14 & 10 & 3 \\
\hline a) Letters sent to MPSJ are managed in hierarchical order & 1 & 3 & 8 & 25 & 10 \\
\hline b) Requirements of building plans are understandable to all stakeholders & - & 11 & 12 & 22 & 2 \\
\hline $\begin{array}{l}\text { c) Clear statutory clocks of building plan approval procedures for related } \\
\text { stakeholders }\end{array}$ & - & 10 & 13 & 21 & 3 \\
\hline $\begin{array}{l}\text { d) Lack of information presented by applicants/consultants during pre- } \\
\text { consultations }\end{array}$ & 1 & 3 & 15 & 23 & 5 \\
\hline TOTAL & 19 & 100 & 160 & 195 & 43 \\
\hline
\end{tabular}


Procedures for building plan applications at MPSJ are transparent and easily accessible. While detailed requirements for building plans and other plans are also easy to understand. Occasionally, there are situations where the requirements of a development is not clearly stated by MPSJ officers which then necessitates further needs for clarification and assistance by superior officers. Overall, most of the building plan applications achieved the levels as expected by most PSP and they are satisfied with the performance of the MPSJ procedures. Staff reshuffling is a common practice in the government that usually worries most PSPs. Hence, mentoring and tutoring should be undertaken by each department to ensure that the successive officer is able to carry out the previous workload and at the same time bear the latest workload. However, a standard method should be created to ensure that replacement officers undergo mentoring and tutoring within a given time frame. This is to ensure they are fully educated and are getting adequate guidance for their new scope of work.

According to one of the respondents, often, the delay of re-submitting the building plans after the consideration of the OSC Committee Meeting is largely due to PSPs themselves. Documents are not re-submitted properly with errors on a meeting decision letter which requires the letter itself to be amended by MPSJ officers. Sometimes, delays occur due to conflict of interest between property developers and MPSJ regarding building plan reviews. For example, if a property developer wants to appeal a compound imposed by MPSJ, it can take a long time if the property developer insists on appealing to get as much discounts as possible for the compound.

The OSC Committee Meeting will send the decision letter to the PSP via postal mail. Typically, the expected time to receive the postal letter is uncertain. Usually within 2 days to 2 weeks. There are times where postal mails do not reach PSPs at all. MPSJ needs to have an online system to help PSPs receive reviews and feedback in shorter time; if possible, as soon as the letter is confirmed by the relevant technical departments. Systems such as SMS, WhatsApp and Email are easy to use and accessible to everyone. Hence, online notifications will save PSPs a lot of waiting time and it is certainly an upgrade from using postal mail.

Currently, all development requirements in MPSJ are enforced by the Town Planning Department, Building Department and Engineering Department, and they are very satisfactory in terms of legislation. Development requirements are also clearly stated by MPSJ. However, the existing property development requirements in MPSJ should begin to change gradually to suit the changing times. The OSC department does not have the skills to make pre-checking and fee calculations. Only documents are reviewed at the OSC Department while fee calculations and pre-checking are carried out according to the department involved. For example, building plans in the Building Department and site layout plan in the Town Planning Department will be calculated separately at the respective departments. Normally, the OSC Department will instruct the PSP to meet officials according to the departments involved with the developments.

\subsection{ROLE of OSC in the local authority}

All respondents are required to give feedbacks on roles of the OSC Department and the efficiency of the related department in handling applications for new developments in MPSJ. The questionnaire aims to identify the capabilities and capacity of the OSC Department to fulfil their roles in MPSJ.

Twenty-two (22) respondents are unsure (46.81\%) whether the public fully understands the current procedures of the OSC Department. However, the respondents agreed that technical departments within MPSJ understand the procedures $(42.55 \%, 20$ respondents) with only sixteen (16) who were unsure (34.04\%). And only eleven (11) respondents believe the internal technical departments do not understand the procedures $(23.41 \%)$. The respondents feel that manpower in the OSC Department of MPSJ is adequate $(44.68 \%, 21$ respondents) but they believe more manpower is needed in the future $(57.45 \%, 27$ respondents). Most of the respondents also believe that officers in the OSC department have the skills $(63.83 \%, 30$ respondents) and the knowledge $(65.96 \%, 31$ respondents) required to manage building plan applications and procedures. However, respondents also believed that OSC officers should possess the ability to instruct PSPs much better because eleven (11) respondents $(23.40 \%)$ do not agree that OSC officers are even equipped to do it, while sixteen (16) respondents (34.04\%) were unsure whether OSC officers are even able to do so. Only twenty (20) respondents (42.56\%) believed that OSC officers are capable of instructing PSPs on the procedures. 
Table 2. Role of OSC in the local authority

\begin{tabular}{|c|c|c|c|c|c|c|}
\hline \multicolumn{2}{|r|}{ Role of OSC in the local authority } & 1 & 2 & 3 & 4 & 5 \\
\hline 1 & Inadequate manpower/staff in OSC & 2 & 13 & 11 & 14 & 7 \\
\hline 2 & OSC needs further reinforcement in manpower & 1 & 7 & 12 & 15 & 12 \\
\hline 3 & Understanding of OSC procedures by other technical departments within MPSJ & 2 & 13 & 22 & 9 & 1 \\
\hline 4 & OSC Officers have skill to manage building plan applications and procedures & - & 11 & 16 & 18 & 2 \\
\hline 5 & Strict regulations for building plan procedures/applications & - & 3 & 14 & 24 & 6 \\
\hline & a) Reviewing building plans/related plans & 2 & 6 & 10 & 24 & 5 \\
\hline & $\begin{array}{l}\text { b) Synchronization of requirements between departments within MPSJ (building, } \\
\text { engineering and town planning department into the plan) }\end{array}$ & 1 & 8 & 11 & 23 & 4 \\
\hline & c) Instruct applicants (architects, engineer and town planners) to amend their plan & 1 & 10 & 16 & 17 & 3 \\
\hline & d) Calculate and endorse amount of monies and fees related to the development & 1 & 11 & 11 & 21 & 3 \\
\hline \multirow[t]{9}{*}{6} & $\begin{array}{l}\text { OSC department officers possess the knowledge required to manage building plan } \\
\text { applications and procedures }\end{array}$ & - & 1 & 15 & 25 & 6 \\
\hline & MPSJ Policies and standing instructions & - & 1 & 15 & 26 & 5 \\
\hline & Related to Uniform Building By-Laws requirements & - & 5 & 11 & 28 & 3 \\
\hline & Related to Road Drainage and Building Act, Act 133 requirements & - & 4 & 11 & 28 & 4 \\
\hline & Related to Town and Country Planning Act, Act 172 requirements & - & 4 & 9 & 30 & 4 \\
\hline & Related to Local Authority Act, Act 171 requirements & - & 3 & 11 & 29 & 4 \\
\hline & OSC Manuals & - & 3 & 6 & 34 & 4 \\
\hline & MPSJ related work procedures & - & 2 & 10 & 31 & 4 \\
\hline & TOTAL & 10 & 105 & 211 & 396 & 77 \\
\hline
\end{tabular}

In this sense, the OSC Department of MPSJ do not have adequate knowledge and skills to handle all the building plan applications, particularly to review the building plans and also to conduct pre-checking for the plans. Most times, they just follow a check-list. The building plans were also often accepted by the OSC Department without any checks conducted on whether the plan fully complied with requirements or not. This is because the OSC Department does not know the significance of the documents. It seems they are not trained to review important matters relating to building plans in general. Without knowledgeable staffs at the front counter, various information cannot be shared with PSPs and the staffs are unable to assist PSPs to better understand submission matters pertaining to legislations and guidelines.

\subsection{OSC procedure and time frame}

This section focus to answer questions in regards to the time frame section listed in the OSC Procedure for processing new building plan applications. It is important to identify whether the officers within the internal technical departments are familiar with the time frame and duration of OSC work procedures.

OSC Department has conducted all the necessary process to inform all stakeholders about the OSC procedures and the duration related to the procedures $(65.96 \%, 31$ respondents). The survey has also shown that the OSC Department has served the purposes that were initially outlined in the year 2007 (63.83\%, 30 respondents). OSC procedures have also helped simplified land related procedures $(55.32 \%, 26$ respondents) and helped create the Concurrent Development Procedures for Build-Then-Sell and Sell-Then-Build developments (51.06\%, 24 respondents).

Nevertheless, the respondents still doubt that the OSC Department ever had a Fast lane Priority for BuildThen-Sell developments because nine (9) respondents (19.14\%) do not agree that it ever existed, while nineteen (19) respondents (40.43\%) were unsure whether the OSC Department ever had a Fast lane procedure. Only nineteen (19) respondents $(40.43 \%)$ believed that it was on the cards. Most of the respondents agreed that the time needed for first checking and review is fourteen (14) days $(78.72 \%, 37$ respondents) and all applications will be brought to the OSC Committee meeting within thirty (30) days (82.98\%, 39 respondents). After the meeting, the respondents believed that the applicants may return the amended plans within sixty (60) days from the date of release of the OSC meeting minutes $(57.45 \%, 27$ respondents). Respondents also feel that most PSPs have been able to return the amended plans on time $(55.32 \%, 26$ respondents $)$ 
Table 3. OSC procedure and time frame

\begin{tabular}{|c|c|c|c|c|c|c|}
\hline \multicolumn{2}{|r|}{ OSC procedure and time frame } & 1 & 2 & 3 & 4 & 5 \\
\hline \multirow[t]{4}{*}{1} & OSC serves the purposes initially outlined in the year 2007 & - & 1 & 16 & 28 & 2 \\
\hline & $\begin{array}{l}\text { a) Fast lane priority for build-then-sell (BKJ) projects (4 } \\
\text { months approval time) }\end{array}$ & - & 9 & 19 & 17 & 2 \\
\hline & Simplified land related procedures & - & 6 & 15 & 23 & 1 \\
\hline & $\begin{array}{l}\text { c) Two simultaneous developments procedure (for BKJ and } \\
\text { sell-then-build JKB) }\end{array}$ & - & 5 & 18 & 23 & 1 \\
\hline \multirow[t]{7}{*}{2} & OSC informs all stakeholders of the procedures and durations & 1 & 4 & 11 & 29 & 2 \\
\hline & The procedures accessible at the counter & - & 5 & 8 & 31 & 3 \\
\hline & The procedures accessible via a website & - & 1 & 7 & 32 & 7 \\
\hline & The procedures accessible via publication & - & 5 & 16 & 24 & 2 \\
\hline & Information/documents required for every application & - & - & 7 & 37 & 3 \\
\hline & The expected time or duration involved for the procedures & - & 1 & 12 & 25 & 6 \\
\hline & In-depth pre-consultation & 1 & 3 & 12 & 25 & 6 \\
\hline 3 & The need for first checking and review is 14 days & - & 2 & 8 & 30 & 7 \\
\hline 4 & Applications were tabled in OSC committee meeting within 30 days & - & 2 & 6 & 30 & 9 \\
\hline 5 & $\begin{array}{l}\text { Applicants return the amended plans within } 60 \text { days from the date of } \\
\text { release of the minutes from the OSC meeting }\end{array}$ & 1 & 7 & 12 & 23 & 4 \\
\hline 6 & Quick return of amended plans from the applicants & - & 6 & 15 & 24 & 2 \\
\hline \multicolumn{2}{|c|}{ TOTAL } & 3 & 57 & 182 & 407 & 56 \\
\hline
\end{tabular}

\section{CONCLUSION AND RECOMMENDATION}

To conclude, delay was the main issue identified in the building plan application in MPSJ. The OSC procedure was the main cause of this delay. This is due to the Principal Submitting Person (PSP) who submitted inadequate documents to OSC that ends up causing the applications to be further delayed. The PSP or the consultant is the key to every successful application. If they do not have an adequate knowledge on development guidelines and regulations, one shall expect instant failure. PSP must be informed on the time limitation and expected time frame of every processes. In order to avoid this failure, every PSP must be well-prepared in regards to any submission of building permit applications. Pre-consultation is the map that will guide PSPs toward the proper physical development journey. There is always a need for constant reform of physical development regulations and the use of information technology to ensure better physical development control and enforcement.

Moreover, the lack of manpower and expertise at the OSC counter need to be solved in order to overcome the delay. The OSC Department in every local authority must function as the centre of excellence particularly for development approvals, where both the department and its personnel must be highly competent and well-versed with all related development matters. This function is important for OSC to have a more defined role. As mentioned earlier, pre-consultation is vital aspect in development process. The OSC Department must always be prepared and able to answer any queries in regards to application of buildings plans. Therefore, the OSC Department must be more involved with development matters as this will surely promote transparency not just within the OSC Department but also in the local authority itself. The knowledge and understanding of these situations serve as a basis for future strategic planning decisions, and as a guide in the planning system delivery of real estate developments, particularly in the Malaysian context.

\section{ACKNOWLEDGEMENT}

The authors would like to thank the National Institute of Valuation (INSPEN) for supporting the study through NAPREC Grant (100-IRMI/GOV16/6/2(011/2018), the Universiti Teknologi MARA (UiTM), all the government departments, organisations and individuals who have contributed to this study

\section{REFERENCES}

United Nations. The World Cities in 2016 Data Booklet. Retrieved from 
www.un.org/en/.../desa/population/.../the_worlds_cities_in_2016_data_booklet.pdf(2016).

Global Construction 2025 Report. Retrieved from https://assets.publishing.service.gov.uk (2013).

United Nations (2017). Sustainable Development Goals. Retrieved from http://www.un.org/sustainabledevelopment/sustainable-development-goals/

Moullier, T. Reforming Building Permits: Why is It Important and What Can IFC Really Do? International Finance Corporation, Washington, DC. (2009).

Hernando, D.S. The Mystery of Capital: Why Capitalism Triumphs in the West and Fails Everywhere Else. Basic Books, New York. (2000)

Laws of Malaysia. Street, Drainage and Building Act (Act 133). Kuala Lumpur: International Law Books Services.

Kincaid D. Adapting buildings for changing uses, guidelines for change of use refurbishment. Spon Press: London. (2003).

Mitropoulos, \& Howell. Renovation projects: Design process problems and improvement mechanisms. Journal of Management in Engineering, 18 (4): 179-185. (2002).

McKim, R. Tarek, H. \& Attalla, M. (2000). Project Performance Control in Reconstruction Project. Journal of Construction Engineering and Management 126 (2): 137-14. (2000).

Nguyen, L.D., Ogunlana, S.O. \& Lan, D.T.X. A study on project success factors in large construction projects in Vietnam. Engineering, Construction and Architectural Management, 11 (6): 404-413. (2004).

Kerzner, H. Project Management: A System Approach to Planning, Scheduling, and Controlling (10th ed.). Van Nostrand, New York. (2009).

Fadzil, M. Penambahbaikan Sistem Penyampaian Prosedur Dan Proses Serta Pelaksanaan Pusat Setempat Bagi Cadangan Pemajuan. Town and Country Planning Department of Malaysia. Kuala Lumpur. (2007)

Ministry of Housing and Local Government, Malaysia Upgrading of the Procedure on the Delivery System and Development Plan Process and the Implementation of the One Stop Centre (2nd ed.). Kuala Lumpur: Malaysia. (2008).

Laws of Malaysia. Local Government Act 1976 (Act 171). Kuala Lumpur: International Law Books Services

Subang Jaya Municipal Council. Retrieved from http://ocps.mpsj.gov.my (2015).

United Nations Sustainable Development (1992) Conference on Environment \&amp; Development (Agenda 21), Rio de Janeiro, Brazil, United Nations. 